\title{
Correction to: Baseline HbA1c Level Influences the Effect of Periodontal Therapy on Glycemic Control in People with Type 2 Diabetes and Periodontitis: A Systematic Review on Randomized Controlled Trails
}

Ya-fei Chen - Qi Zhan · Chen-zhou Wu • Yi-hang Yuan •

Wen Chen · Fan-yuan Yu $\cdot$ Yi Li $\cdot$ Long-jiang Li (D)

Published online: March 27, 2021

(C) The Author(s) 2021

\section{Correction to: Diabetes Ther https://doi.org/10.1007/s13300- 021-01000-6}

In the original article, there are two first authors, Ya-fei Chen and Qi Zhan.

The original article has been updated.

Ya-fei Chen and Qi Zhan are co-first authors of this study.

The original article can be found online at https://doi. org/10.1007/s13300-021-01000-6.

Y. Chen · Q. Zhan · C. Wu · Y. Yuan - W. Chen . F. Yu · Y. Li · L. Li $(\bowtie)$

State Key Laboratory of Oral Diseases and National Clinical Research Center for Oral Diseases, West China Hospital of Stomatology, Sichuan University, Chengdu, China

e-mail: lilongjiang63@163.com

Y. Chen · Q. Zhan · C. Wu · Y. Yuan - W. Chen ·

Y. Li · L. Li

Department of Head and Neck Oncology, West China Hospital of Stomatology, Sichuan University, Chengdu, China

F. Yu

Department of Endodontics, West China Hospital of Stomatology, Sichuan University, Chengdu, China
Open Access. This article is licensed under a Creative Commons Attribution-NonCommercial 4.0 International License, which permits any non-commercial use, sharing, adaptation, distribution and reproduction in any medium or format, as long as you give appropriate credit to the original author(s) and the source, provide a link to the Creative Commons licence, and indicate if changes were made. The images or other third party material in this article are included in the article's Creative Commons licence, unless indicated otherwise in a credit line to the material. If material is not included in the article's Creative Commons licence and your intended use is not permitted by statutory regulation or exceeds the permitted use, you will need to obtain permission directly from the copyright holder. To view a copy of this licence, visit http://creativecommons.org/licenses/by$\mathrm{nc} / 4.0 /$. 